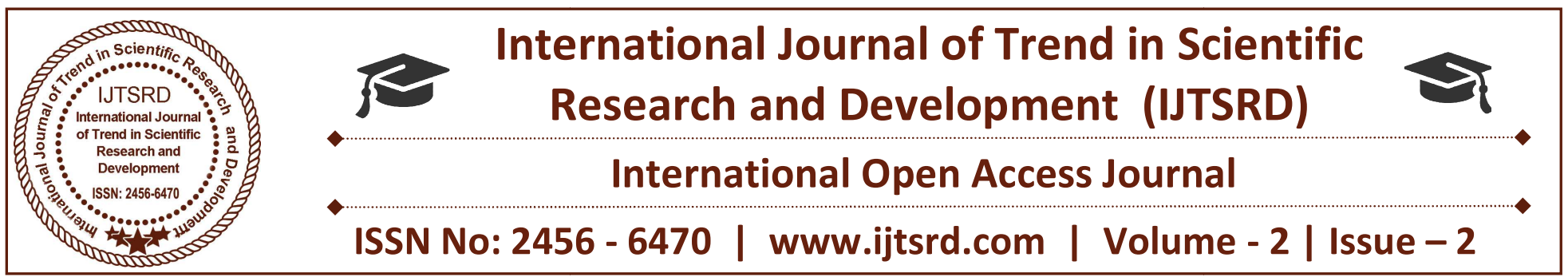

\title{
A Descriptive Research on the Contributing Factors in Mutual Fund Investment Across India
}

\author{
Dr. Dipa Mitra \\ Associate Professor \& Former Head, M.Phil. \& Ph.D \\ Programme, IISWBM, Kolkata, West Bengal, India
}

\begin{abstract}
Present study aims to identify the most significant factors in mutual fund investment across India. In this regard a descriptive research is performed to find out the most contributing factors in determining the motivation level of the prospective investors regarding their investment in mutual fund and to investigate their influencing level for the same. Reliability Test has been done checking internal consistency of data, Principal Component Analysis is used to identify major factors, Confirmatory Factor Analysis is applied to frame a model hypothesised on the factors to check the goodness of fit of the model, Regression Analysis is executed to investigate their influence level and to frame an equation on the basis of the same. Lastly different scenario and causal analysis have been depicted with the help of Bayesian Probabilistic Network to establish an overall framework for mutual fund investment strategy implementation.
\end{abstract}

Keywords: Mutual Fund Investment, Confirmatory Factor Analysis, Bayesian Probabilistic Network, Indian Insurance Sector

\section{INTRODUCTION}

Today, Mutual Funds has become a extensively accepted and powerful way for the investors to contribute in financial markets in a comparatively trouble-free, economical fashion, while minimising risk depicts by distribution of investment across various kinds of securities, also called as diversification. It has occupied a vital role in an individual's investment plan. They offer the potential

for capital growth and income through investment performance, dividends and distributions under the guidance of a portfolio manager who makes investment decisions on behalf of mutual fund unit holders. Over the past decade, mutual funds have increasingly become the investor's vehicle of choice for long-term investment. Investment decisions are always very crucial as it's directly related with risks and return. Indian Mutual fund industry has performed substantial expansion since its initiation in 1963. The remarkable increase in the Indian Mutual fund industry in current years can mostly be credited to a range of factors such as constructive tax schemes, and induction of numerous new products, mounting household savings, wide-ranging regulatory framework, investor's knowledge movement and function of distributors. To make investment decisions in mutual funds majority of investors consider many factors which are non-performance related variables. It is evident that a small group of investors appears to be highly knowledgeable about their investments whereas most investors appear to be ignorant, having little knowledge of the investment plans or financial details about their investments. Sometimes when people pay fees to equity mutual fund for investment they think that they are reducing the return that they would otherwise achieve by investing in a non managed index fund that tracks the total stock market .Customer's psychology, consumer behaviour, and behavioural finance literatures effect consumer choices about mutual funds. Many studies were undertaken to understand the reasons behind spending money on actively managed mutual 
funds and it was identified that the reasons for their investments were that most people overestimated both the future performance and the past performance of their investments. People overestimated the consistency of portfolio performance. In this context Present study aims to identify the most significant factors in mutual fund investment decisions. In this regard a descriptive research is performed to find out the most contributing factors in determining the motivation level of the prospective investors and to investigate their influencing level for the same.

\section{LITERATURE REVIEW}

Jones et al $(2007)^{8}$ showed the relationship between advertising, quality, and price in the mutual fund market. This research studies the purchase decision for investors, whether investors can infer mutual fund quality and price from the presence of mutual fund advertising. Post-advertising period shows a negative relationship between advertising and fund used, indicating that previously advertised funds shows weaker performance than non advertised funds. During the post-advertisement time both equity and fixed income funds exhibit lower costing than non advertised funds. K John, et al (2008) ${ }^{7}$ conducted the study with the objective that whether a modified method of supplemental information disclosure impacts investors' fund evaluations and investment intentions. It shows that while investors continue to place too much emphasis on prior performance, the provision of supplemental information and investment knowledge to influence perceptions and evaluations of mutual funds.Gillt, Nahum, Harminder, Gill ${ }^{5}$ (2011) conducted a study based on a sample of people living in Punjab and Delhi .Investment expertise, general knowledge about the economy and the concept of mutual fund consultation with investment advisors. Family size also plays the role to invest in mutual funds. The valuable and useful recommendations for the investment managers and investment advisors have also been provided in the paper. Barreda et al ${ }^{2}$ (2011) made a study to understand the consumer's behaviour towards socially responsible mutual funds. It was found that individuals' criteria for investment are essentially guided by returns and diversification, participants invest significantly more in a fund when they are explicitly informed about its social responsible in nature. Chen Hui-chuan $(2011)^{3}$ out a research to see that the relationship between mutual funds 'net assets, share prices, manager tenures, expense ratio, tax - cost ratio and annualized returns to investigate whether Consumer Reports is an authentic source for people planning to invest in mutual funds. Gatzert, , Carin and Hato ${ }^{4}$ (2011 )shows that even though the majority of the participants are significantly lower on average than the prices obtained using a financial pricing model. A considerable portion of participants is still willing to pay a substantially higher price. Kaurinderjit, KaushalK.P. ${ }^{6}$ (2016) made a study that in India the investment in mutual funds is very less as compared to other developing countries. This research's objective is to understand the factors that control investment behaviour of investors towards mutual funds. This research said that investment behaviour is influenced by awareness, perception and socioeconomic characteristics of investors. Risk perception for mutual funds had no effect on the investment decision. Age, gender, occupation, income and education of investors had an impact on the awareness about mutual funds. Acharya et al $(2017)^{1}$ shows that the present study focus on the past studies conducted by various academicians, researchers to know the investor's preference towards mutual funds. Various literatures are studied to judge the perfect mutual fund for investment.Reepu ${ }^{9}$ (2017) performed a study to know about Mutual Fund, its various schemes and analyse the different risk factors involved in investing in mutual funds.

\section{OBJECTIVES}

- To identify the most dominating factors in determining the motivation level of the prospective investors

- To investigate their influencing level for the same in Indian mutual fund setor.

- to develop a framework which may lead to policy implementation on the basis of the above factors

\section{METHODOLOGY}

A questionnaire is designed to gather data from the 456 investors from all four regions of India to identify the factors that are of prime concern to invest in mutual fund. A descriptive research is done to identify the factors of importance to investors.

RELIABILITY TEST has been done checking internal consistency of data, PRINCIPAL COMPONENT ANALYSIS is used to identify major factors, CONFIRMATORY FACTOR ANALYSIS is applied to frame a model hypothesised on the factors to check the goodness of fit of the model, 


\section{INTERPRETAION OF CONFIRMATORY FACTOR ANALYSIS}

\section{Result (Default model)}

Minimum was achieved,

Chi-square $=76.257$

Degrees of freedom $=8$

Probability level $=.000$

Table 3: Model Fit Summary

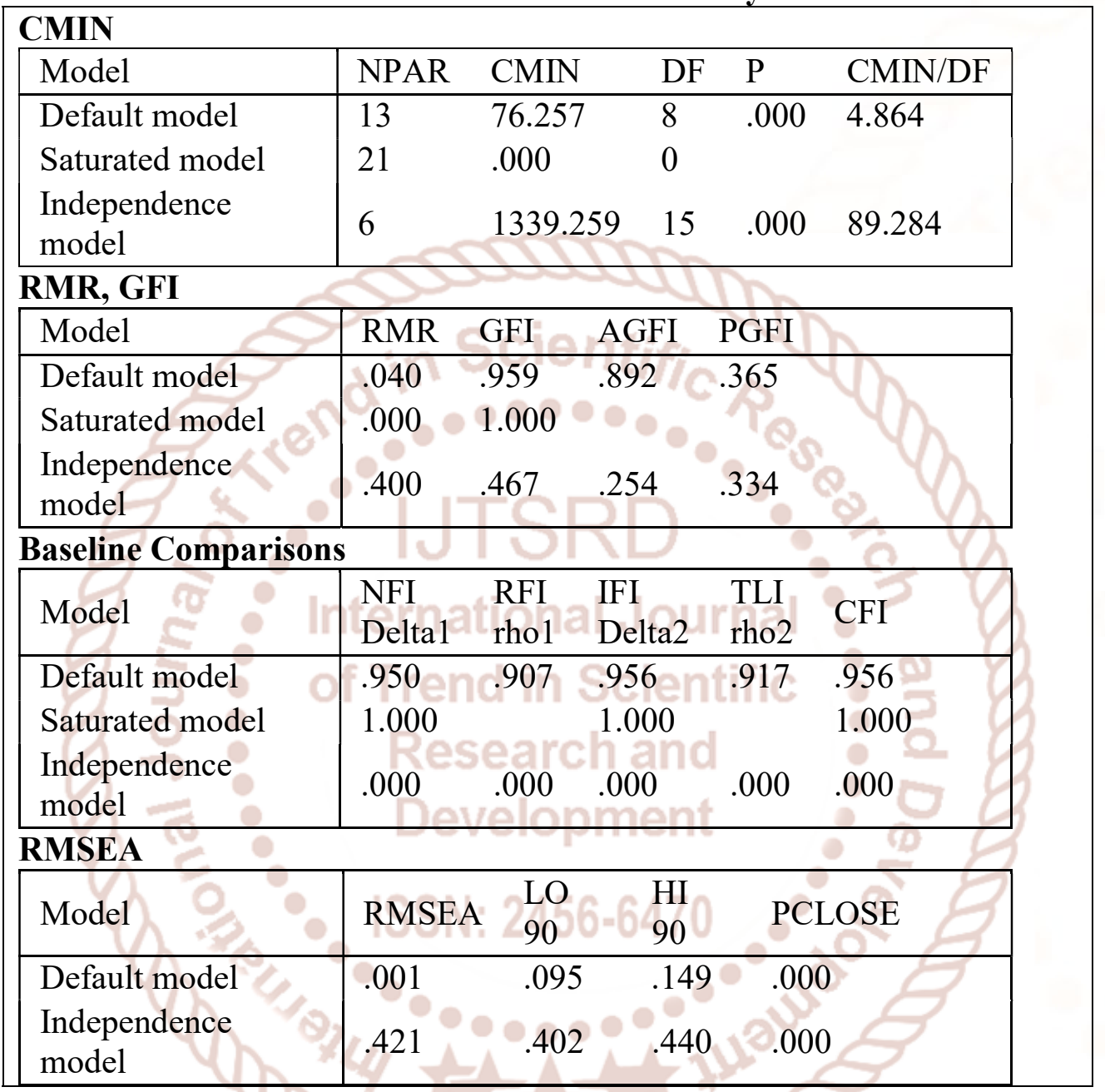

This model indicates a good fit. The CMIN table shows a value of less than .5 indicating a good fit for the model. The GFI shows an acceptable value of more than .95. The NFI and CFI score (.950 and .956 respectively) also indicates a good fit of the model. The RMSEA value of (.001) confirms a good fit of the hypothesised model. This shows minimum difference between the sample covariance and the original covariance of the model.

\section{INTERPRETAION OF MULTIPLE REGRESSION ANALYSIS:}

A regression analysis is done on the major factors extracted by factor analysis to find its impact on the overall motivation level. It can be seen that there exist a significant impact of interaction with teachers and extracurricular activities in assessing the overall satisfaction level.

It is observed from regression that Financial Awareness (38.52\%), Frame of Mind (28.70\%) and Trust $(24.24 \%)$ are the most dominating factors influencing overall motivation level with respect to mutual fund investments which corroborates with the result of factor analysis. 
So the regression equation can be drawn as :

Motivation towards Investment in Mutual Fund $=1.340+0.385$ Financial Awareness +0.287 Frame of Mind +0.242 Trust

\section{INTERPRETATION OF BAYESIAN PROBABILISTIC NETWORK:}

As part of initiative for further research, the empirical analysis has been recast in terms of Bayesian Probabilistic Framework. The independent factors - financial awareness, frame of mind and trust - have binary measures from the available evidence and a probability distribution of the dependent variableMotivation towards Investment in Mutual Fund - occupies and completes the Bayesian framework. As it's an well known fact that Bayesian Probabilistic frameworks provide an elegant solution, particularly in cases of limited data and when qualitative and/or a mix of qualitative and quantitative data need to be used. This is precisely the case in the current investigation. The basic framework is given in the following diagram. A spectrum of scenario and causal analyses follows.

\section{BAYESIAN PROBABILISTIC NETWORKS}

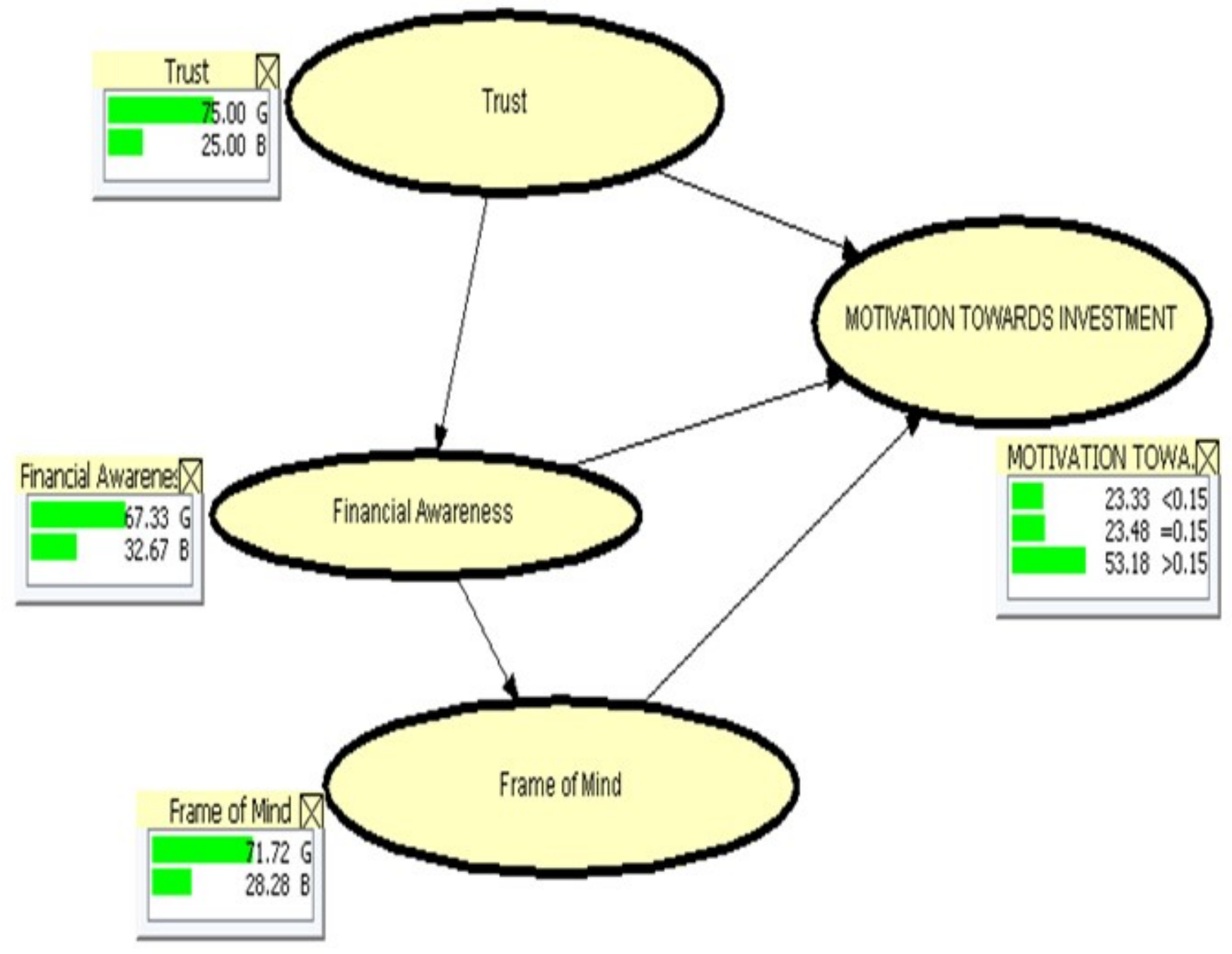


International Journal of Trend in Scientific Research and Development (IJTSRD) ISSN: 2456-6470

\section{SCENARIO ANAYSIS \& CAUSAL ANALYSIS:}

\section{SCENARIO ANAYSIS I}

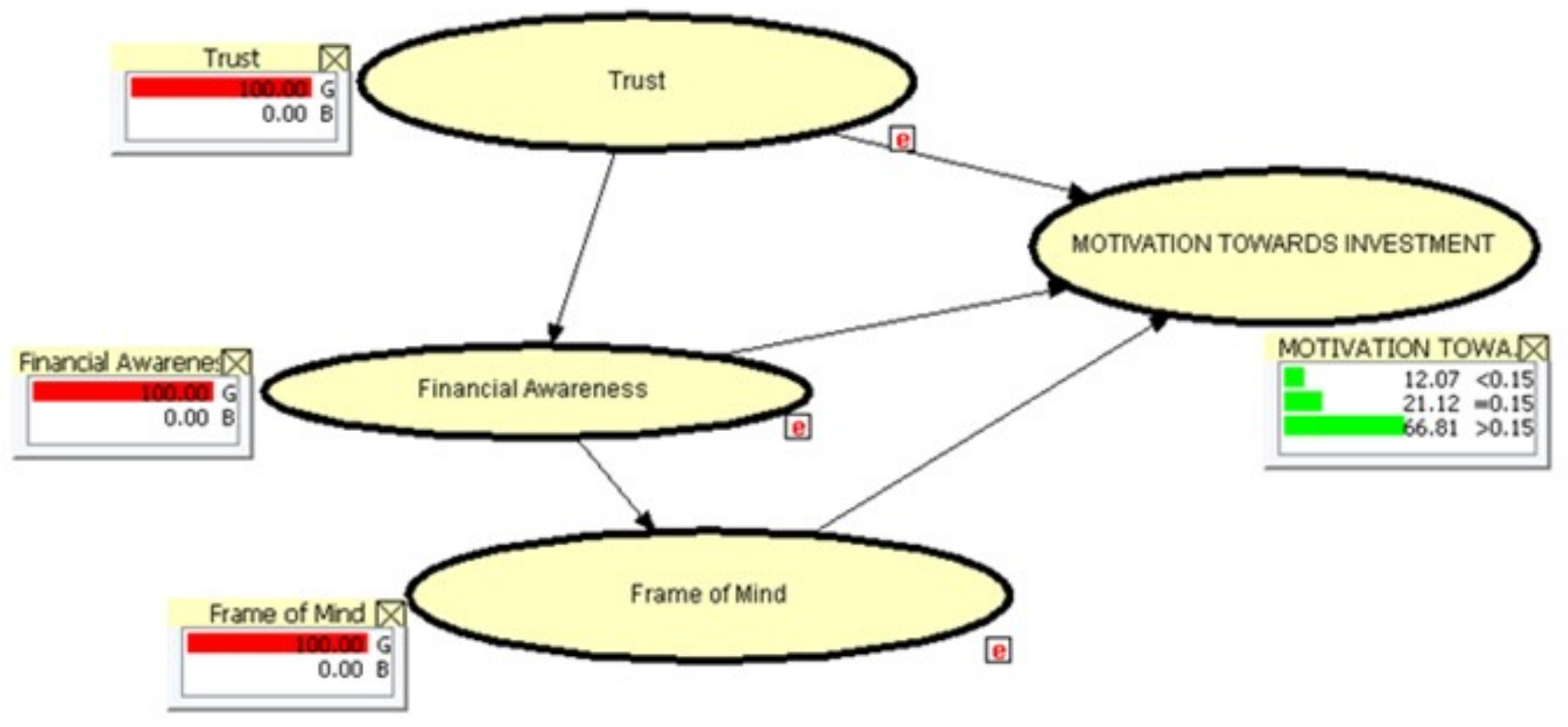

\section{SCENARIO ANAYSIS II}

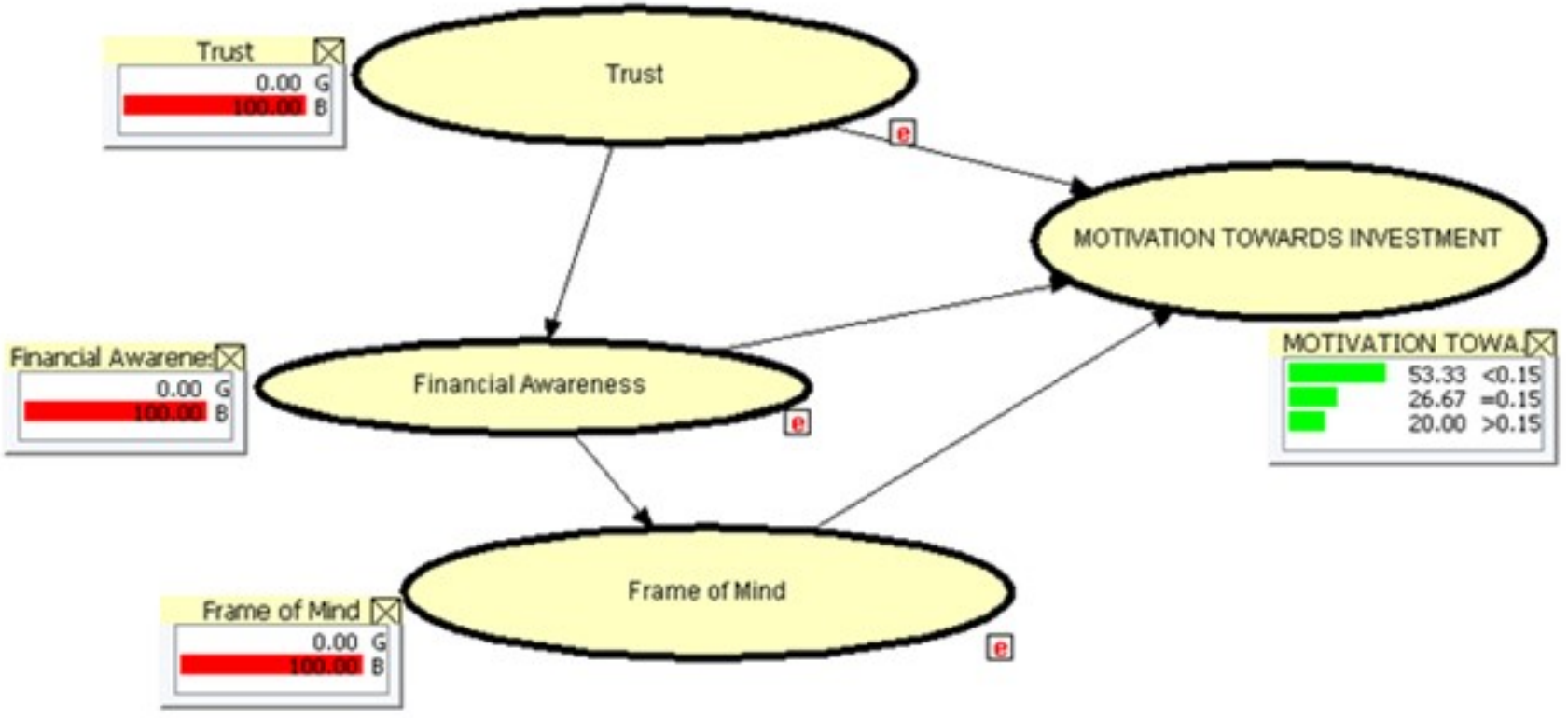


International Journal of Trend in Scientific Research and Development (IJTSRD) ISSN: 2456-6470

\section{CAUSAL ANALYSIS I:}
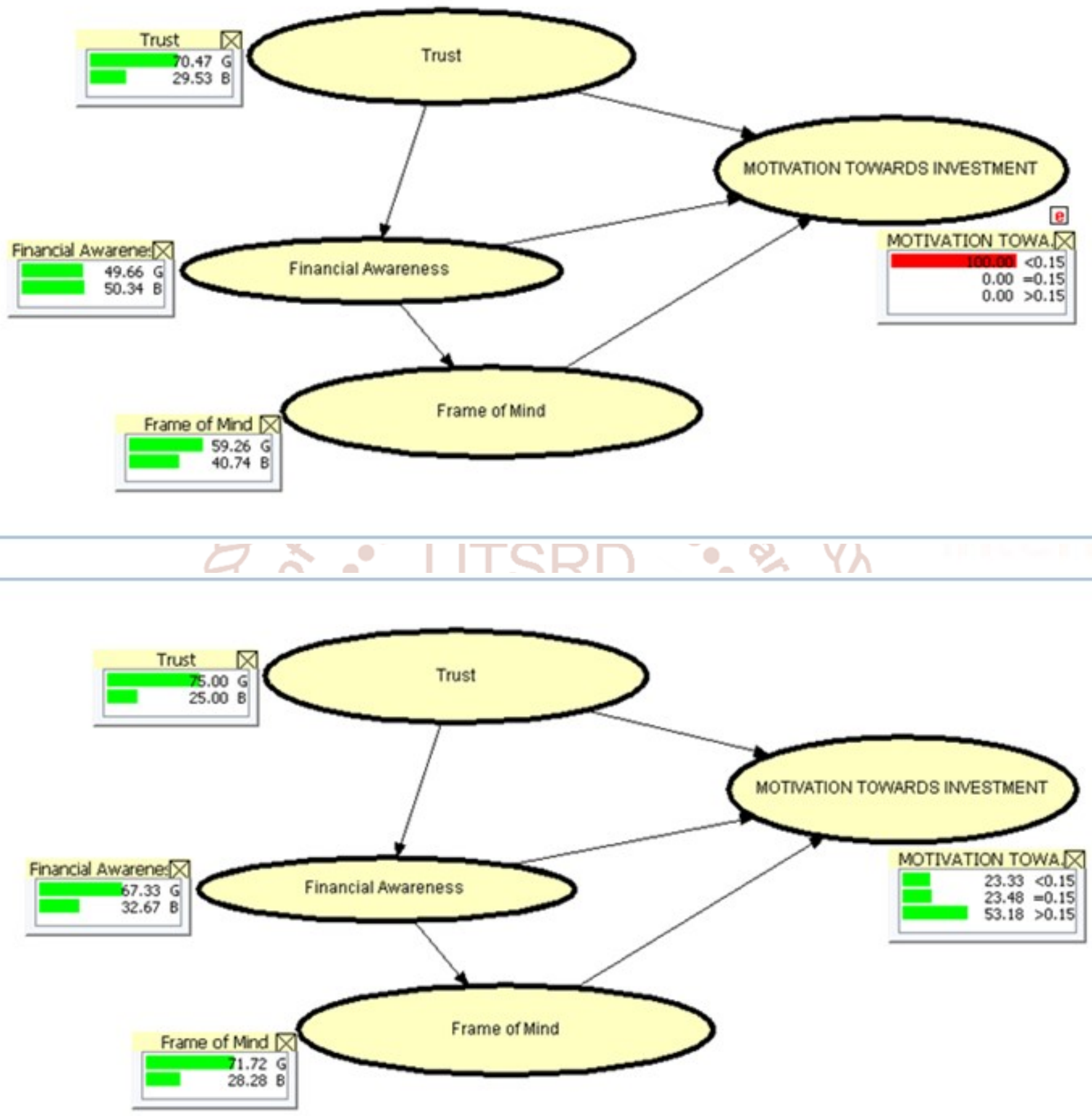
International Journal of Trend in Scientific Research and Development (IJTSRD) ISSN: 2456-6470

\section{CAUSAL ANALYSIS II:}
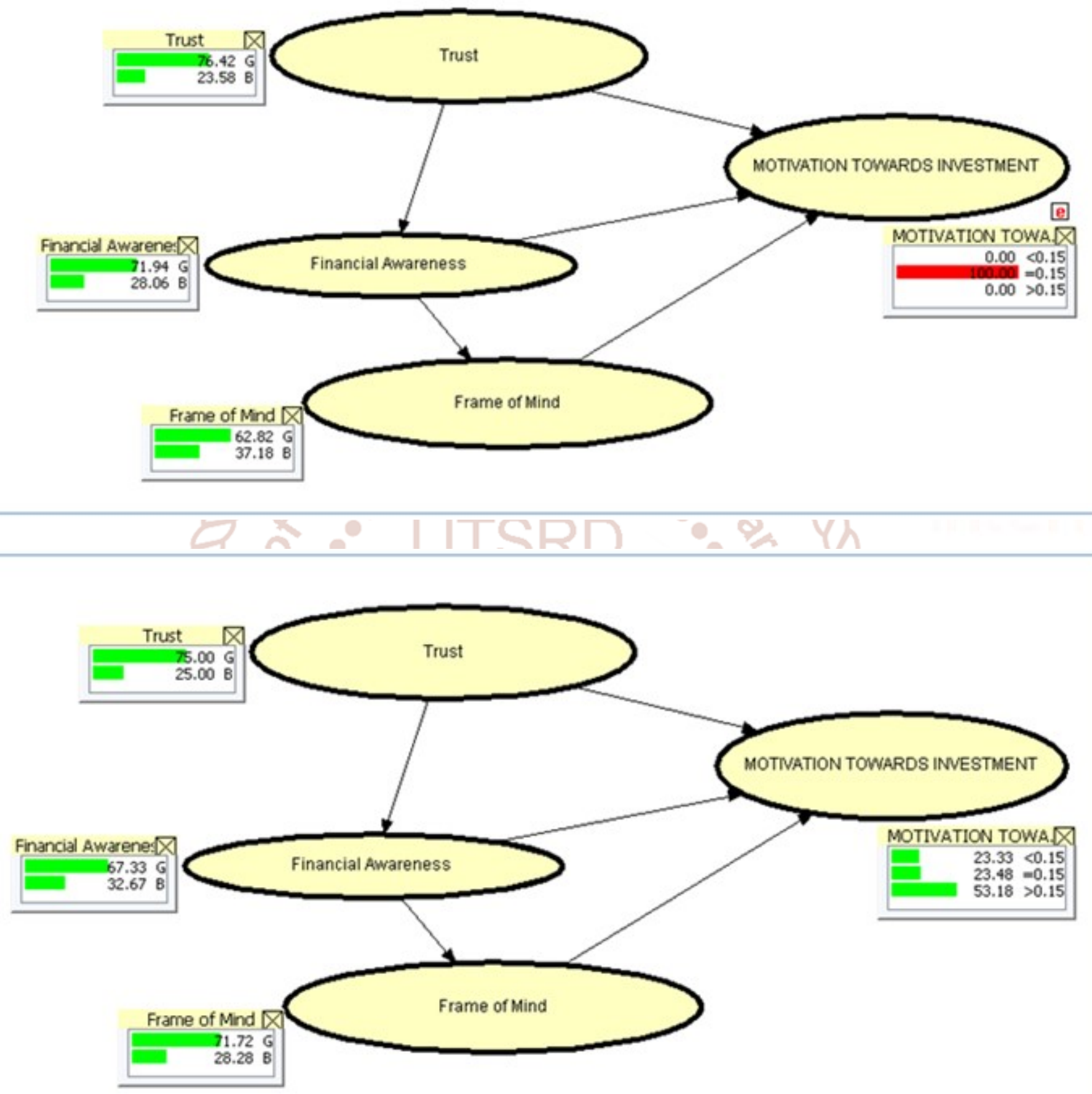

@ IJTSRD | Available Online@www.ijtsrd.com | Volume-2 | Issue - 2 | Jan-Feb 2018 


\section{CAUSAL ANALYSIS III:}

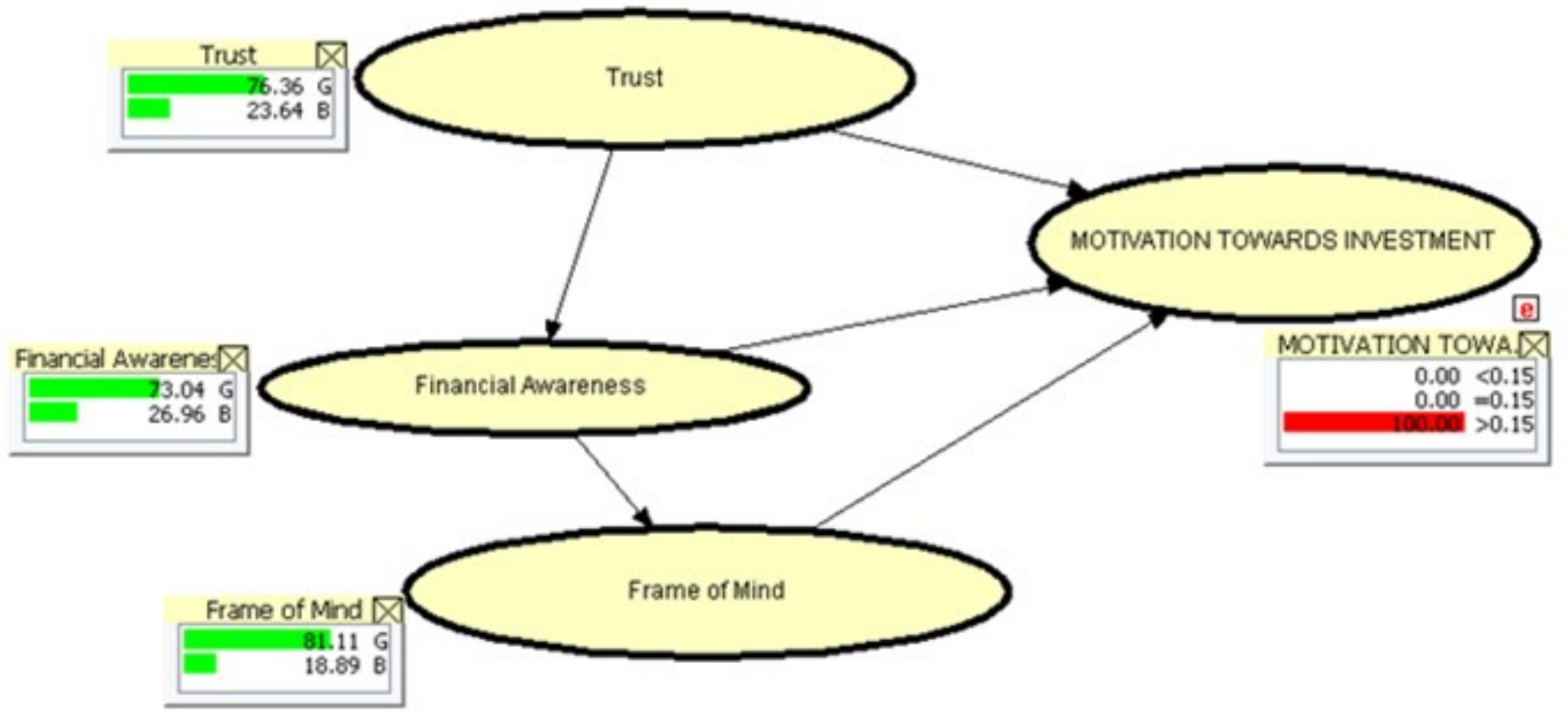

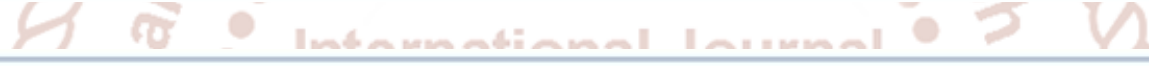

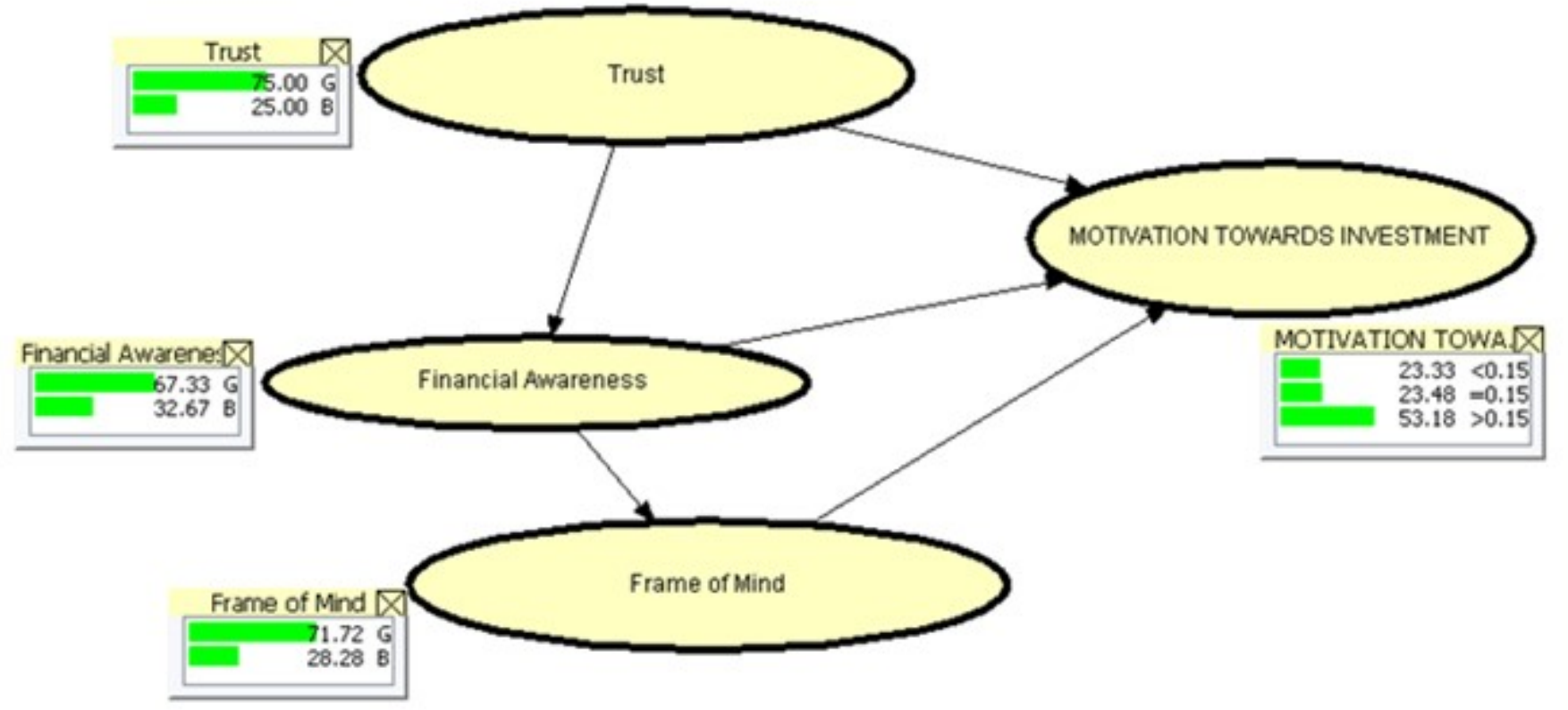

\section{CONCLUSION}

\section{SCENARIO AND CAUSAL ANALYSIS:}

With Scenario Analysis, one can calibrate one or more causal or independent factors in the network and analyze its impact on the Motivation towards Investment in Mutual Fund estimate. For example, one might be interested in high Financial Awareness, Frame of Mind and Trust to check how these changed level affect dependent variable; other might like to check how the low score in the independent variables convert the scores of the dependent variable. 
Under Causal Analysis, new evidence of Motivation towards Investment in Mutual Fund is used to calculate updated probabilities (also referred to as posterior probabilities) of all the causal/ independent factors. In other words, additional Motivation towards Investment information is propagated to all the nodes in the network. This technique of evidence (new Motivation towards Investment data) propagation is extremely useful for analyzing the causes that impact Motivation towards Investment in Mutual Fund.

The Bayesian process of statistical estimation is one of continuously revising and refining the probable influences of the independent Financial Awareness, Frame of Mind and Trust related factors about the state of the outcomes regarding Motivation towards Investment in Mutual Fund as more data become available.

\section{RESEARCHER'S NOTE:}

So this research lays the foundation of an Investment model for the Indian investors; most significant factors and their influencing levels have been identified by principal component analysis and multiple regression. Bayesian analysis lays down different scenarios are available to them where they can find out how the highest or lowest value of the most significant factors like Financial Awareness, Frame of Mind and Trust affect on the lowest, moderate and highest level of Motivation towards Investment in Mutual Fund; on the contrary, a Causal analysis at the end clearly discerns what levels of the significant factors would obtain desired values of Motivation towards Investment for the Indian mutual fund companies.

\section{REFERENCES}

1. Acharya, Krishna Kavitha; Das, Kishore Kumar(2017)'"Literature Review on Investors' Preference towards Mutual Funds" International Journal of Management \& IT; Bhubaneswar Vol. 4, Iss. 5, (May 2017): 22-29

2. Barreda et al. (2011)'Measuring Investors' Socially Responsible Preferences in Mutual Fund"Journal of Business Ethics (2011) 103:305330 DOI 10.1007A10551-011-0868-Z.

3. ChenHui-chuan(2011)"Analysis of Consumer Reports' recommended mutual funds compared to actual performance" Journal of Financial Services Marketing; Basingstoke Vol. 16, Iss. 1, (Jun 2011): 42-49.
4. Gatzert Nadine, Huber Carin and SchmeiserHato (2011 )"On the Valuation of Investment Guarantees in Unit-linked Life Insurance: A Customer Perspective'The Geneva Papers on Risk and Insurance. Issues and Practice,Vol. 36, No. 1 (January 2011), pp. 3-29.

5. Gill Amarjit, BigerNahum,MandS.Harminder, Gill S. Sukhinder (2011) "Factors that affect mutual fund investment decision of Indian investors"International Journal of Behavioural Accounting and Finance $>$ List of Issues $>$ Volume 2, Issue 3-4 > DOI: 10.1504/IJBAF.2011.045020

6. Kaurinderjit, Kaushal K.P.(2016)'Determinants of investment behaviour of investors towards mutual funds" Journal of Indian Business Research, Vol. 8 Issue: 1, pp.19-42

7. Kozup John, Howlett Elizabeth And Pagano Michael(2008)"The Effects of Summary Information on Consumer Perceptions of Mutual Fund Characteristics"The Journal of Consumer Affairs, Vol. 42, No. 1 (Spring 2008), pp. 37-59 Published by: Wiley Stable URL:

8. Michael A. Jones, Vance P. Lesseig, Thomas I. Smythe, Valerie A. Taylor(2007) "Mutual fund advertising: Shouldinvestors take notice?'Journal of Financial Services Marketing; Basingstoke Vol. 12, Iss. 3, (Dec 2007): 242-254.

9. Reepu (2017)"A Study Of Mutual Funds"International Journal of Management (IJM) Volume 8, Issue 3, May-June 2017, pp.213-219 